\title{
Prevalence and risk factors of tobacco abuse in Rishikesh
}

Deepak Kumar $^{1}$; Surekha Kishore ${ }^{2}$; Meenakshi Khapre ${ }^{3}$; Mahendra Singh ${ }^{4}$; Bhavna Jain ${ }^{5}$; Ajeet Singh Bhadoria ${ }^{6}$ ${ }^{1} J u n i o r$ Resident, Department of Community and Family Medicine, All India Institute of Medical Sciences, Rishikesh; ${ }^{2} \mathrm{Head}$ and Professor, Department of Community and Family Medicine, All India Institute of Medical Sciences, Rishikesh; ${ }^{3}$ Assistant Professor, Department of Community and Family Medicine, All India Institute of Medical Sciences, Rishikesh; ${ }^{4}$ Assistant Professor, Department of Community and Family Medicine, All India Institute of Medical Sciences, Rishikesh; ${ }^{5}$ Senior Resident, Department of Community and Family Medicine, All India Institute of Medical Sciences, Rishikesh; ${ }^{6}$ Assistant Professor, Department of Community and Family Medicine, All India Institute of Medical Sciences, Rishikesh

\begin{tabular}{|c|c|c|c|c|c|c|c|c|}
\hline Abstract & Introduction & Methodology & Results & Conclusion & References & Citation & \multicolumn{2}{|c|}{ Tables / Figures } \\
\hline \multicolumn{9}{|c|}{ Corresponding Author } \\
\hline \multicolumn{8}{|c|}{$\begin{array}{l}\text { Dr Deepak Kumar, Department of Community and Family Medicine, All India Institute of Medical Sciences, } \\
\text { Rishikesh. } \\
\text { E Mail ID: deepakkumar1786@gmail.com }\end{array}$} & 回㬏四 \\
\hline
\end{tabular}

\section{Citation}

Kumar D, Kishore S, Khapre M, Aggarwal P, Singh M, Jain B. Prevalence and risk factors of tobacco abuse in Rishikesh: A community based observational study. Indian J Comm Health. 2020;32(1):164-166.

Source of Funding: Nil Conflict of Interest: None declared

Article Cycle

Received: 08/03/2020; Revision: 17/03/2020; Accepted: 23/03/2020; Published: 31/03/2020

This work is licensed under a Creative Commons Attribution 4.0 International License.

\section{Abstract}

Introduction: Tobacco is the most common form of substance abuse. Commonest evil of modern society is use of tobacco, though alcohol is equally harmful as tobacco but the accessibility of tobacco and its product are far easier for any individua. Aim \& Objective: To determine the prevalence of tobacco abuse in the community and its association with sociodemographic factors of study participants. Materia \& Methods: A community based cross-sectional study was conducted among 804 study participants of age group $15-60$ years in Rishikesh, Uttarakhand. Since the population of urban and rural area is almost equal, so to get equal representative 402 study participants were selected from each area. Data was collected in MS Excel and analyzed using SPSS version 23 using appropriate statistical techniques like percentage, chi-square test and $p$-value. Results: Overall prevalence of substance abuse was found to be $37.4 \%$ out of which the prevalence of current users was $31.34 \%$. Conclusion: Present study revealed that in spite of having strict law for prohibition of substance abuse, people are still addicted. There is a need to change either in law or in behavior of people at large.

\section{Keywords}

\section{Prevalence; Risk Factors}

\section{Introduction}

According to World Drug Report 2014, about 243 million people (range 162 million -324 million) used an illicit drug (for e.g: opioid, cocaine, cannabis, amphetamine-type stimulant) corresponding to $5.2 \%$ of world population of age group 15-64 years (1). According to Global Health Observatory (GHO) data over 1.1 billion people smoked tobacco in 2015 (2). Moreover a report by WHO on the global tobacco epidemic 2008 has mentioned that, tobacco alone has killed around 100 million people in the 20th century and continue to kill 5.4 million people every year and is expected to rise to 8 million per year by 2030, $80 \%$ of which will occur in the developing countries like India (3). GATS (Global Adult Tobacco Survey)-1 India had shown as alarming fact of tobacco consumption in more than one-third of adults (4). Tobacco consumption is higher among lower socio-economic groups, which is visible in terms of the lower age of initiation, more consumption, and lower quit rates. Prevalence of tobacco use has decreased by 6 percent from $34.6 \%$ in GATS- 1 (2009-2010) to $28.6 \%$ in GATS -2 (2016-2017). Also $29.6 \%$ of men, $12.8 \%$ of women and $21.4 \%$ of all adult currently use smokeless tobacco. $42 \%$ of men, $14.2 \%$ of women and $28.6 \%$ of all adults either smoke tobacco or use smokeless tobacco (5).

\section{Aims \& Objective}

1. To determine the prevalence of tobacco abuse in the community

2. To find out association of tobacco abuse with sociodemographic factors 


\section{Material \& Methods}

A community based cross sectional study was conducted from April 2018 to November 2019 in Rishikesh, Uttarakhand. Study was approved by institutional ethical committee. The sample size was calculated using prevalence of substance use as $61 \%$ with an allowable error of $5 \%$ and confidence interval of $95 \%$ as 366 . A nonresponse rate of $10 \%$ was added to this, so the final sample size was 402 . Multistage sampling method was used. So, a design effect of 2 was added making final sample size of 804 . Since the population of urban and rural area is almost equal, so to get equal representative, 402 study participants were selected from each urban and rural area respectively. Written informed consent was obtained from each participant. Standardized and validated interview schedule was used for data collection. Inclusion Criteria: Population of 15-60 years age group of both sexes

Exclusion Criteria: Refusal to participate, non cooperative subjects, Mentally Retarded people, Migrants or residing since less than one year

Statistical methods: The data was entered into MS excel sheet 2013 and exported to IBM SPSS (statistical package for social sciences) version 23 for analysis. Association between tobacco abuse and socio-demographic variable of study participants was calculated by chi square statistics. $\mathrm{P}$ value less than 0.05 percent was considered statistically significant.

Working definitions: Ever user: The respondents who accepts having tobacco ever in life and Current user: The respondent, who accepts having used of tobacco in the past 3 months.

\section{Results}

A total of 804 study participants were enrolled for the study, 402 study participants from urban area and rural area each with 410 (51\%) males and 394 (49\%) females. The socio-demographic details are depicted in (Table 1). The mean age of study participants was $38.71( \pm 13.45)$ years, the mean age of male and female study participants were $41.65( \pm 13.57)$ years and $35.64( \pm 12.68)$ years respectively.

Among tobacco users around $51 \%$ belongs to age group 45-60 years, $(p<0.0001)$. Prevalence of tobacco abuse was high among males and this difference was found to be statistically significant $(p<0.0001)$. Also, those who were unemployed (68\%) consumed more tobacco and this difference was statistically significant $(p<0.0001)$. Educational status of study participants and their socioeconomic class (modified BG Prasad) was not found to be associated with tobacco user

Prevalence of tobacco abuse was $33.95 \%$ in ever users and $28.48 \%$ in current users and prevalence of substance abuse in urban and rural areas in ever users was 34.3 and 33.58 respectively and current users was $26.4 \%$ and $30.6 \%$ respectively (Table 2 )

\section{Discussion}

In present study, the prevalence of current use of tobacco was $28.48 \%(n=229)$ in the study participants, Finding of present study was lower than the Grill et al. (38.9\%).(6), Grill conducted his study in mountainous and rural region of Uttarakhand where prevalence of tobacco may be more due to easy availability and cultural acceptability. Result of present study was almost similar to Rani et al. (7) (2003) from Jaipur.

In present study, prevalence of current use of tobacco was $6.1 \%$ in female participants. This is more or less similar to the finding reported by NFHS-4 india fact sheet (8) (6.8\%) but finding of the present study is higher than the finding reported by NFHS-4 Uttarakhand fact sheet (9) (2.9\%). Rani et al. (7) from Jaipur in 2003, reported prevalence of tobacco use was $13.8 \%$, which is higher than the present study (6.1\%). Giovino et al. (10) analyze the GATS data in 2010 , finding of the study was $11.3 \%$ which is higher than the present study (6.1\%).

The prevalence of tobacco use in present study in rural areas among males was $58.6 \%$ and among female was $9.5 \%$ respectively, result of present study was higher if compared with finding of NFHS-4(national family health survey) 2015-2016 Uttarakhand fact sheet(9), (prevalence of tobacco in male $=46.6 \%$, female $=2.9 \%$,). Rani et al. (7) has conducted a study, tobacco users among males was $50.9 \%$ and among females was $15.5 \%$, finding of this study was lower as compare to male participant of present study (58.6) but higher as compare to female participant of present study (6.1).

\section{Conclusion}

Prevalence of tobacco use in present study was 33.95\% in ever user and $28.48 \%$ in current user. Prevalence of tobacco use was lower in urban area as compared to rural area.

\section{Recommendation}

Present study revealed that in spite of having law for prohibition of tobacco abuse, people are still addicted. There is a need to change either in law or in behavior of people at large. People should be educated about the hazardous impact of substance on health and society. Display of advertisement depicting harmful effects, effectively dealing with peer pressure, increasing the price of tobacco and Complete ban of advertisement on any kind of substance should be implemented.

\section{Limitation of the study}

In this study, age group of study participants was 15 to 60 years. Participants below 18 years interview was taken in the presence of parents due to ethical consideration. Thus, it is possible that many participants of this age group (15 to 18 years age group) may not have accepted the use of substance in presence of parents. 


\section{Relevance of the study}

Despite of extensive use of tobacco/alcohol/cannabis, data on prevalence and risk factors of substance abuse in India is limited especially in the female population. Therefore, the current study has been conducted to shed light on substance abuse in Uttarakhand.

\section{Authors Contribution}

All authors have contributed equally.

\section{Acknowledgement}

The authors are grateful to the study participants for their cooperation and participation in the study.

\section{References}

1. Global Health Observatory data, WHO, Available from: http://www.who.int/gho/ tobacco/ use/ en/, accessed on 20 October 2019.

2. Global status report on alcohol. Geneva: World Health Organization; 2004, The World health report 2002 - reducing risks, promoting healthy life. Geneva: World Health Organization; 2002

3. World Health Organization, Research for International Tobacco Control. WHO report on the global tobacco epidemic, 2008: the MPOWER package. World Health Organization; 2008 Feb 11.
4.

Ministry of Health and Family Welfare, Government of India. Global Adult Tobacco Survey (GATS), India, Report, 2009-2010. Available from, http://www.aftcindia.org/pdf/File\%2010.pdf accessed on 20 October 2019. accessed on 20 October 2019.

5. Ruhil R. India has reached on the descending limb of tobacco epidemic. Indian journal of community medicine: official publication of Indian Association of Preventive \& Social Medicine. 2018 Jul;43(3):153-56.

6. Grills NJ, Singh R, Singh R, Martin BC. Tobacco usage in Uttarakhand: a dangerous combination of high prevalence, widespread ignorance, and resistance to quitting. BioMed research international. 2015;(2015):1-10

7. Rani M, Bonu S, Jha P, Nguyen SN, Jamjoum L. Tobacco use in India: prevalence and predictors of smoking and chewing in a national cross-sectional household survey. Tobacco control. 2003 Dec 1;12(4): e4-

8. National Family Health Survey-4, State Fact Sheet, Uttarakhand, 2015-16:1-6

9. National Family Health Survey -4, India Fact Sheet, 2015-16,1-4

10. Giovino GA, Mirza SA, Samet JM, Gupta PC, Jarvis MJ, Bhala N, Peto R, Zatonski W, Hsia J, Morton J, Palipudi KM. Tobacco use in 3 billion individuals from 16 countries: an analysis of nationally representative cross-sectional household surveys. The Lancet. 2012 Aug 18;380(9842):668-79.

\section{Tables}

\begin{tabular}{|c|c|c|c|c|c|}
\hline & variables & Number $(n)$ & $\begin{array}{c}\text { Tobacco } \\
\text { abuser }\end{array}$ & $\begin{array}{c}\text { Percent } \\
(\%)\end{array}$ & $\varkappa^{2} \mathrm{df}, \mathrm{p}$ value \\
\hline \multirow[t]{3}{*}{ Age group } & $15-30$ & 248 & 32 & 12.90 & \multirow{3}{*}{$\begin{array}{c}x^{2}=92.5 \\
d f=2 \\
p<0.0001\end{array}$} \\
\hline & $30-45$ & 245 & 81 & 33.06 & \\
\hline & $45-60$ & 311 & 160 & 51.44 & \\
\hline \multirow[t]{2}{*}{ Sex } & Male & 410 & 238 & 58.04 & \multirow{2}{*}{$\begin{array}{c}x^{2}=216.5 \\
d f=1 \\
p<0.0001\end{array}$} \\
\hline & female & 394 & 35 & 8.8 & \\
\hline \multirow[t]{7}{*}{ Educational status } & Professional degree & 42 & 10 & 23.8 & \multirow{7}{*}{$\begin{array}{c}x^{2}=8.71 \\
d f=6 \\
p=0.190\end{array}$} \\
\hline & Post graduate or graduate & 158 & 39 & 29.10 & \\
\hline & Intermediate & 159 & 54 & 33.94 & \\
\hline & High school & 149 & 48 & 32.21 & \\
\hline & Middle school & 116 & 43 & 37.06 & \\
\hline & Primary school & 79 & 36 & 45.56 & \\
\hline & illiterate & 101 & 43 & 34.95 & \\
\hline \multirow[t]{5}{*}{ occupation } & employed & 273 & 156 & 57.14 & \multirow{6}{*}{$\begin{array}{c}X^{2}=265 \\
d f=4 \\
P<0.0001\end{array}$} \\
\hline & unemployed & 25 & 17 & 68 & \\
\hline & studying & 110 & 12 & 10.9 & \\
\hline & retired & 73 & 59 & 80 & \\
\hline & homemaker & 323 & 29 & 8.97 & \\
\hline \multirow{5}{*}{$\begin{array}{c}\text { Socioeconomic } \\
\text { Class(BG Prasad } \\
\text { scale) }\end{array}$} & Upper class & 103 & 39 & 37.8 & \\
\hline & Upper middle class & 245 & 64 & 26.12 & \multirow{4}{*}{$\begin{array}{c}X^{2}=10.5 \\
d f=4 \\
P=0.33\end{array}$} \\
\hline & Middle class & 347 & 131 & 37.75 & \\
\hline & Lower middle class & 91 & 31 & 34 & \\
\hline & Lower class & 18 & 8 & 34.6 & \\
\hline
\end{tabular}

\section{TABLE 2 DISTRIBUTION OF STUDY PARTICIPANTS ACCORDING TO TYPE OF TOBACCO USE. (N=804)}

\begin{tabular}{|l|c|c|c|}
\multicolumn{1}{|c|}{ Types of Tobacco use } & \multicolumn{2}{c}{ Place of residence } & Total (804) \\
& Rural (402) & Urban (402) & No (\%) \\
\hline Ever user & No (\%) & No (\%) & $273(33.95)$ \\
\hline Current user & $138(34.3)$ & $135(33.58)$ & $229(28.48)$ \\
\hline
\end{tabular}

